\title{
CONTRIBUIÇÕES DA ÉTICA PARA A GOVERNANÇA CORPORATIVA
}

Bruna Faccin CAMARGO ${ }^{1}$

Branca BARCELLOS ${ }^{2}$

Ieda Márcia Donati LINCK ${ }^{3}$

Vanessa Steigleder NEUBAUER ${ }^{4}$

${ }^{1}$ Contadora, Graduada em Ciências Contábeis (UNICRUZ), Mestranda em Desenvolvimento (UNIJUI). Email: brunafaccinflor@hotmail.com

${ }^{2}$ Graduada em Ciências Contábeis Universidade de Cruz Alta, Pós-Graduanda em Controladoria, Perícia e

Auditoria (IMED) Email: brancacamargo@hotmail.com.

${ }^{3}$ Graduada em Letras Português/Inglês pela (UNICRUZ), Especialista em Leitura e Produção Textual pela (UNICRUZ), Mestre em Educação pela (UNINORTE), Mestre em Linguística pela (UPF), Doutoranda em Linguística pela (UFSM), docente Universidade de Cruz Alta. E-mail: imdlinck@gmail.com

${ }^{4}$ Graduada em Dança pela (UNICRUZ), Especialista em Psicopedagogia Clínica e Institucional Especialista pela (UNICRUZ), em Mídias na Educação pela (UFSM), Mestre em Educação nas Ciências pela (UNIJUI), Doutoranda em Filosofia pela (UNISINOS), docente Universidade de Cruz Alta. E-mail: borbova@gmail.com

Recebido em: 30/05/2014 - Aprovado em: 20/09/2014 - Disponibilizado em: 15/12/2014

\begin{abstract}
Resumo
Este trabalho trata da ética ligada à governança corporativa, um tema de importância relevante, amplamente discutido nos últimos anos. A ética tem como objeto de estudo as atitudes dos seres humanos, suas ações, os costumes adotados, a moral. Alguns temas podem ser destacados como de interesse da ética, como a liberdade, a dignidade humana, a autonomia, a consciência. O relacionamento entre as pessoas, como indivíduos ou grupos, é foco central de atenção da ética e da moral. Poucos assuntos têm sido tão discutidos nas organizações, no mundo inteiro, quanto a ética corporativa. $\mathrm{O}$ estudo proposto, de caráter bibliográfico, tem como autores principais Silva, Dupont, Valls, Calil e Vieira, cujas considerações são fundamentais sobre este assunto. O estudo será subdividido em dois momentos, sendo o primeiro, "Luzes aos princípios conceituais da ética", como principio filosófico, estabelece a construção da vida humana intrinsecamente ligada a ética, ao passo que suas interações somente se põe sólidas através da mesma, dando consistência às relações desde os primórdios até a atualidade. $\mathrm{Na}$ atualidade, é uma necessidade o conhecimento básico e a compreensão da mesma, para que em qualquer momento seja de uma forma ou de outra praticado atos justos, embasados na ética. No segundo, "A governança corporativa e sua necessidade do "ser" ético", tendo a ética abrangendo espaço elevado na gestão de governança corporativa, ao passo que tem por intuito o fortalecimento das relações estabelecidas entre as empresas e seus diversos públicos.
\end{abstract}

Palavras-chave: Ética. Governança Corporativa. Informação. Sistema.

\section{CONTRIBUTIONS OF ETHICS TO THE CORPORATE GOVERNANCE}

\begin{abstract}
This work addresses the connected ethical to corporate governance, a topic of relevance importance, discussed extensively in recent years. Ethics has as its object of study the attitudes of human beings, their actions, the assumed behavior, the moral, like the freedom, the human dignity, the autonomy, the conscience. The relationship between people, as individuals or groups, is the central focus to attention of ethic and moral. Few subjects have been so discussed in organizations, around the world, like the corporate ethics. The proposed study, of bibliographical character, had as main authors Silva, Dupont, Valls, Calil e Vieira, whose
\end{abstract}


considerations are essentials on this subject. The study will be subdivided in two moments, the first, "Lights to the conceptual principles of ethic", like philosophic principle, establishes the construction of human life intrinsically linked to ethical, while that their interactions just be comes solid through the same, giving consistency to relations from the beginnings to the present. Today, it is need the basic knowledge and understanding of the same, so that at any moment independent of the way, will be practiced righteous deeds grounded in ethics. In second, "Corporate governance and the need of the "being" ethical", having ethics covering important space in the management of corporate governance, while that have purpose at strengthening relations between companies and their various public.

Keywords: Ethics. Corporate Governance. Information. System.

\section{Introdução}

É necessário, em qualquer relação estabelecida, desde as mais singelas até as mais sofisticadas informações sobre negócios, o surgimento de parâmetros que constituam organização e respeito entre essas relações. Para que isso seja vivenciado de forma efetiva é importante que a ética esteja implícita em cada ser envolvido, considerando que ela é diretriz da ordem e limites, e assim estabelecerá consistência e veracidade a tudo que for definido e acordado.

A ética permite-nos refletir e, acima de tudo, construir e não destruir a sociedade em que estamos inseridos. É de suma importância estabelecer o bem comum, acima do bem de um indivíduo, ela prima pela estruturação da liberdade e a firmeza das interações humanas. Ela se materializa pela vontade de ordem e respeito de uma sociedade (aquilo que ela valoriza), que é construída e refletida pelas suas ações e práticas do dia a dia. A ética como uma ciência procura orientar a conduta humana. Para Dupont (2010, p. 19), " a ética tem seu objeto próprio, suas próprias leis e métodos. O objeto da ética é a moral, tendo como parte integrante o comportamento humano". As premissas básicas são de regular a vida em sociedade para que os sujeitos que a constituem possam conviver melhor. É, portanto, o principal regulador do desenvolvimento histórico-cultural da humanidade. Tão extensa é a atuação dos princípios éticos que, praticamente, nenhuma área de ação lhe escapa, estabelecendo vínculos até mesmo no mundo das empresas.

Esse texto ilustra aspectos pertinentes à ética e sua relevância na informação, demonstrando a importância dos conceitos da mesma para a correta dispersão das informações na prática da governança corporativa, discorrendo sobre os diversos conceitos relacionados e aprofundando-se de modo que, sucintamente, haja a compreensão de que a ética e a governança corporativa são 
conceitos que se complementam mutuamente e um não pode prescindir dos princípios do outro. Além disso, alinhamse os conceitos éticos aos princípios que norteiam a governança corporativa e suas atividades de divulgação de informações, chamando a atenção para os problemas pertinentes a essas divulgações, por ser uma busca pelos conceitos de ética e seus preceitos, no que tange as atividades desenvolvidas pela governança corporativa de uma entidade.

A contabilidade prevê impressão nas demonstrações contábeis previstas em leis e em relatórios, todavia por meio dessa ciência social podem-se extrair outras informações, que giram em torno, e podem ser utilizadas pelas práticas de governança até chegarem aos seus usuários fins. No entanto, observa-se, que conforme o meio em que está implantada a entidade, os contadores tendem a se sentir pressionados pela administração para o gerenciamento e a ajuste do resultado. Isso vai contra os princípios contábeis e a ética profissional, todavia embasados nos princípios éticos da profissão, não devem sujeitar-se a tais pressões, por estarem cientes da função social que detêm, ao lidar com informações que interferem na empresa e na sociedade.

O estudo será subdividido em dois momentos, sendo o primeiro, "Luzes aos princípios conceituais da ética", como princípio filosófico, estabelece a construção da vida humana intrinsecamente ligada à ética, ao passo que suas interações somente se põem sólidas através da mesma, dando consistência às relações, desde os primórdios até a atualidade. Justifica-se, pois pela necessidade de todos terem o conhecimento básico e a compreensão sobre a mesma, para que em qualquer momento seja, de uma forma ou de outra, praticado atos justos, embasados na ética. O segundo, "A governança corporativa e sua necessidade do "ser" ético", trata da ética como espaço elevado na gestão de governança corporativa, que tem por intuito $\mathrm{o}$ fortalecimento das relações estabelecidas entre as empresas e seus diversos públicos.

\section{Luzes aos princípios conceituais da ética}

A necessidade de se comunicar e de se fazer entender faz com que o indivíduo busque formas de transmitir sua "mensagem". A partir do momento que a sociedade emergiu do estado de primitivismo para a constituição de grupos familiares, aldeia e posteriormente cidades, aflorou-se a necessidade do 
desenvolvimento de normas e regras de conduta.

Seguindo com a evolução da humanidade foi aperfeiçoado e regulamentado direitos e obrigações para estabelecer um convívio pacífico entre os povos $\mathrm{e}$ as comunidades. Após a Revolução Industrial as empresas iniciaram um novo momento, no qual se exigiu orientações sobre os trabalhos a fim de ajustar as relações entre as entidades. Segundo Silva (2006, p. 91), “pode-se dizer que um dos efeitos da economia globalizada é adotar padrões éticos e morais mais rigorosos, por que as empresas precisam manter uma boa imagem diante do público ou por motivos de demandas diretas do mesmo".

A ciência aristotélica, que é mais nobre das ciências, comporta duas partes que, por conveniência, podemos designar por ética e política. $\mathrm{O}$ estagirita nunca se refere à ética como ciência independente; repostase apenas ao " estudo do caráter".Afinal, á ética de Aristóteles é social: nela o filósofo não se esquece de que o homem individual é membro da sociedade. Por outro lado sua política é ética, pois concebe a virtude da polis como devendo ser conforme à virtude dos cidadãos.Aristóteles, contudo, se dá conta da diferença entre a ética e a política, embora ao elucide claramente a natureza da relação entre ambas.No início da Ética a Nicômaco descreve o bem do Estado como sendo mais importante e perfeito que o do indivíduo. Adverte, porém, que, não podendo atingir aqueles, temos de nos contentar com este. Todavia, no fim da obra, exprimi-se como se o Estado estivesse a serviço da vida moral de cada indivíduo (NEDEL, 2009, p.183).

Embora suas acentuadas variantes históricas, a ética conserva algumas noções sólidas como a distinção entre o bem e o mal, sendo que agir eticamente é agir de acordo com o bem. Orientar-se para que nossos atos não interfiram no bem-estar do outro, faz com que prevaleça a ordem e o respeito mútuo, estabelecendo o foco físico e mental de cada indivíduo.

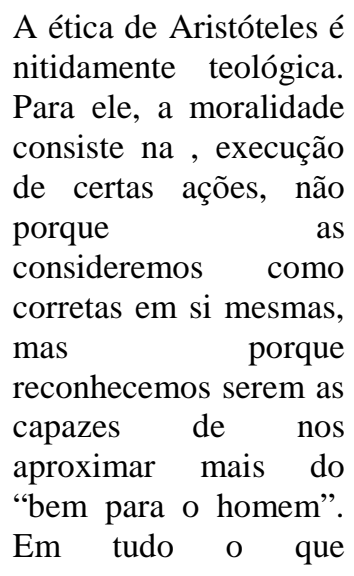

A ética de Aristóteles é nitidamente teológica. Para ele, a moralidade consiste na , execução de certas ações, não porque as consideremos como corretas em si mesmas, mas porque reconhecemos serem as capazes de nos "bem para o homem". Em tudo o que 
fazemos, nos perguntamos pelo fim em virtude do qual agimos. Aliás, "não ter sua vida organizada na direção de algum fim, é um sinal de grande loucura" (NEDEL, 2009, p.184).

Nessa perspectiva, o aprendizado da ética não se apoia em ensinar o que é certo ou errado, mas conduzir os indivíduos da complexidade moral perante as escolhas, não só no mundo dos negócios. A valorização da ética é uma tendência mundial e uma exigência adotada pelas organizações, logo, o estudo da ética nas instituições, empresas e no ensino superior é uma consequência natural. Desde o berço somos ensinados o que é certo e errado, convenções e costumes.

É visto que a finalidade da ética não é só o conhecer, mas também o agir: tornar os homens melhores (jjá são bons). Não é suficiente só dizer o que é o bem, também importar agir bem.Entre o saber (teoria de práxis) e o agir (práxis) há diferença ética fundamental (contra Sócrates). O homem, ser comunitário, encontra-se num mundo já interpretado. Suas práxis no primeiro momento é acrítica. Pela reflexão toma distância e passa atuar à luz da compreensão das razões que justificam seu modo de proceder. Isso para agentes significa um passo ruma à transparência da ação e a seu aperfeiçoamento moral (NEDEL， 2009, p.185).

Grande parte dos valores da sociedade coincide com os valores de seus habitantes, tornando seus objetivos adaptados uns aos outros. Além dos valores individuais, os valores da sociedade serão os valores dos negócios, da necessidade, da descoberta, da inovação e da iniciativa pessoal. Os negócios, o modo como esses estimulam a produtividade e a distribuição de bens por toda a sociedade definirão a própria estrutura e o caráter da sociedade.

$\begin{aligned} & \text { Para Aristóteles, a } \\ & \text { virtude (arete) é } \\ & \text { qualquer execelencia }\end{aligned}$
ou potenciação valiosa
de uma faculdade ou de
um ato. O prefixo ari
de areté significa
perfeição. "A virtude
em geral é uma
excelência ou perfeição
qualquer radicada em
qualquer ente e em
qualquer de seus
atributos, o ponto de
madureza". Comporta
um saber e um querer
(NEDEL, 2009, p.187). 
Deve-se em qualquer situação, principalmente no mundo dos negócios, manter-se um ser ético, com inúmeras virtudes, as quais levarão não só à excelência pessoal, quanto à excelência da organização.

\begin{abstract}
A virtude moral ou do caráter é "um habito eletivo que consiste em um termo médio relativo a nós, determinado por uma regra racionalmente estabelecida como o faria $\mathrm{O}$ homem prudente. O domínio das virtudes morais ora é um tipo de sentimento, ora um tipo de ação. Assim, a virtude moral é uma tendência para controlar certa classe de sentimentos ou para agir corretamente em determinadas situações. Suas aquisição é pela prática ou exercício constante. " Os estados de caráter são formandos por atividade similares" (NEDEL, 2009, p. 188).
\end{abstract}

A ética é totalmente inalterável por parte de alguns indivíduos, como algo inato a nós e nada do que nos acontecer irá modificá-la ou interferi-la. É pensada como se fosse uma lista pré-definida de bons comportamentos e quem fosse capaz de segui-la estaria agindo eticamente. Contudo, os indivíduos que desejem ser éticos devem se preocupar com a sociedade e o contexto histórico-social no qual está inserido. Em algum momento, o avaliar ético poderá ser modificado por uma variação neste cenário.

\section{A governança corporativa e a necessidade do "ser" ético}

A Governança Corporativa é uma exímia ferramenta de gestão, pois é nela que todos os usuários da empresa se apoiarão para diminuir os efeitos da assimetria informacional, atribuindo importância idêntica aos interesses de todas as partes da organização. Para Silva (2006, p. 13), “as informações são primordiais para dar sustentação nas tomadas de decisões, nos processos e o desempenho da organização. É fundamental que haja sintonia entre os controles das operações da empresa e a contabilidade".

$$
\text { O estudo da Governança }
$$

Corporativa é conduzido, basicamente, por uma série de princípios, sobretudo aqueles concernentes à: transparência; equidade; prestação de contas; cumprimento das leis e, maiormente, ética na condução das 
empresas, bem como nas atividades exercidas por governos e entidades não governamentais. Segundo Silva (2006, p. 90), "as empresas terão de aprender a equacionar a necessidade de alcançar lucros, obedecer às leis, ter comportamento ético e envolver-se em alguma forma de filantropia para com as comunidades em que se inserem".

A governança corporativa pode ser entendida como uma ferramenta de apoio à gestão das empresas e instituições, sendo um meio de harmonização de suas atividades. Através dela, os interessados buscam informações acerca das realizações da organização.

Sistema pelo qual as organizações são dirigidas, monitoradas e incentivadas, envolvendo os relacionamentos entre proprietários, conselho de administração, diretoria e órgãos de controle. As boas práticas de governança corporativa convertem princípios em recomendações

objetivas, alinhando interesses com a finalidade de preservar e otimizar o valor da organização,

facilitando seu acesso ao capital e contribuindo para a sua longevidade. (IBGC, 2013, não paginado).
Nesse percurso, Shleifer e Vishny (apud Lopes 2012, p. 170) entendem a GC "como formas pelas quais os fornecedores de recursos financeiros ás firmas asseguram-se de que terão o retorno de seus investimentos".

Para Silva (2006, p.16), a governança corporativa "é um conjunto de práticas que tem por finalidade otimizar o desempenho de uma companhia, protegendo investidores, empregados e credores , facilitando, assim, o acesso ao capital".

Andrade e Rossetti (2004, p. 23) corroboram com os demais, acrescentando que existem diversas expressões-chaves, ligadas a princípios, aos modelos, às práticas, aos mecanismos de regulação e aos propósitos da governança corporativa, sendo os principais: Direito dos acionistas (shareholders); Direito de outras partes interessadas (stakeholders); Conflitos de agência; Sistema de relações; Sistema de Valores; Sistema de governo; Estrutura de poder; Estrutura de regulação; e Padrões de comportamento.

Os conceitos giram em torno do acompanhamento e divulgação dos atos e fatos da empresa, e meios pelos quais a mesma define para controle e publicação para assegurar que os interessados pelas 
informações as recebam de forma coerente

e transparente.

Pela diversidade de partes interessadas, fica evidente que, embora em sentido restrito, a governança responde aos interesses dos acionistas e dos agentes mais diretamente envolvidos com as operações corporativas; em sentido amplo ela pode abranger um conjunto maior de relações de uma corporação de negócios com todos os agentes direta ou indiretamente alcançados por suas ações (ANDRADE E ROSSETI, 2004, p. 21).

Para entendimento sobre as partes interessadas se faz necessária a definição dos tipos de governança, nos termos de shareholder e stakeholders. O primeiro define-se pela propriedade do empresário e pela forma predominante de financiamento das empresas pelo trinômio propriedadegestão-retorno. $\quad \mathrm{O}$ segundo está compromissado com objetivos mais amplos, e não delimitados aos de natureza econômico-financeira, levando em conta não somente os resultados, mas também as consequências dos mesmos.

\footnotetext{
A base da

diferenciação clássica de governança está em shareholder $\mathrm{e}$
}

stakeholders. A

primeira é voltada para os acionistas, enquanto a segunda é de maior abrangência; além dos interesses dos acionistas, consideramse também os interesses dos públicos interno e externo (SILVA, 2006, p. 18).

\section{Para complementar, o IBGC}

(2013):

\begin{abstract}
Shareholders
correspondem a grupos que podem afetar ou serem afetados, de modo significativo, pela empresa, incluindo os próprios acionistas. Enquanto os stakeholders são todas as partes interessadas que devem estar de acordo com as práticas de governança corporativa executadas pela empresa. São elas: os empregados, clientes, fornecedores, credores, governos, entre outros, além dos acionistas.
\end{abstract}

De acordo com a definição de Siffert (1998), a governança corporativa é a forma com que os controladores estabelecem mecanismos de monitoramento e controle em relação aos administradores e fazem com que estes hajam de acordo com o interesse dos controladores. Lodi (2000, p.24) coloca 
que "a relação entre propriedade e gestão se dá através do conselho fiscal, instrumentos fundamentais para $\mathrm{O}$ exercício do controle. A boa governança assegura aos sócios equidade, transparência, responsabilidade pelos resultados (accountability) e obediência ás leis do país".

Os benefícios da boa governança corporativa são claramente reconhecidos pelas empresas participantes, principalmente nos aspectos relativos a aprimorar a transparência, melhorar a gestão da empresa, melhorar a imagem da empresa, permitir o alinhamento entre os acionistas e executivos e facilitar o acesso a capital (IBGC, 2009, p. 01).

A governança corporativa nesse cenário apresenta-se como uma ferramenta de suma importância para o "agente", onde o mesmo emprega as políticas definidas, na busca por aperfeiçoar, gerir e fornecer ao acionista o retorno esperado pelo seu investimento. Dessa forma possibilita a redução dos custos dos conflitos entre administradores e proprietário do capital, para que cada vez mais haja uma harmonia nessa relação.

\section{Teoria da agência}

Devido às mudanças na estrutura das organizações existem variações da forma de definir suas atuações e estratégias, por meio da internacionalização de normas e procedimentos de gestão, que refletem na governança.

\footnotetext{
Não existe um modelo único de governança corporativa. Modelos alternativos, resultantes de valores moldados sob influencia dos traços culturais e institucionais das nações, de sua formação econômica e de seus estágios de desenvolvimento empresarial,

implicando propósitos corporativos de diferentes amplitudes, processos de maior ou menor alcance quanto aos agentes envolvidos e diferentes composições das forças de controle das corporações (ANDRADE E ROSSETI, 2004, p. 98).
}

Logo, os acionistas ou proprietários estão delegando algumas ou a totalidade das diretrizes para um ou mais responsáveis que irão tomar a frente das decisões. Lodi (2000, p. 24) "no passado recente, nas empresas privadas $\mathrm{e}$ 
familiares, os acionistas eram gestores, confundindo em sua propriedade e gestão. Com a profissionalização, a privatização, a globalização e o afastamento das famílias, a governança corporativa colocou $\mathrm{o}$ Conselho entre a Propriedade e a Gestão." Nesse entendimento surge a Teoria da Agência que procura em sua relação maximizar o valor do empreendimento, a riqueza dos acionistas e o retorno de seus investimentos. Essa Teoria pode ser definida como um contrato no qual uma ou mais pessoas - o principal engajam outra pessoa - o agente - para desempenhar alguma tarefa em seu favor, envolvendo a delegação de autoridade para tomada de decisão pelo agente (JENSEN E MECKLING apud IBGC 2013).

Os administradores
podem ser
considerados agentes
dos proprietários que
os contrataram e lhes
conferiam autoridade
para tomar decisões e
administrar
negócios.
Tecnicamente falando,
qualquer administrador
que detenha menos de
100\% da empresa é, em
certo grau, um agente
dos demais
proprietários
(GITMAN, 2010, p.
16).

De acordo com Mendes (2001, apud ARRUDA, 2008):

$\begin{array}{lr}\text { A Teoria da Agência } \\ \text { analisa os conflitos e } \\ \text { custos resultantes da } \\ \text { separação } & \text { entre } \\ \text { propriedade e controle } \\ \text { de capital. } & \text { Essa } \\ \text { possibilidade de não } & \text { do } \\ \text { participação } & \text { no } \\ \text { acionista } & \text { da } \\ \text { gerenciamento } & \text { bem } \\ \text { empresa é } & \text { bela } \\ \text { representada } & \text { pela } \\ \text { sociedade por ações, } \\ \text { que limita } \\ \text { responsabilidade } \\ \text { acionista para com a } \\ \text { organização à parcela } \\ \text { de capital que ele } \\ \text { investiu. }\end{array}$

A Teoria da Agência trata, então, da transferência de riqueza entre principal e agente, ocorrida quando o primeiro delega poderes e autoridade para o segundo tomar decisões; momento em que surge a possibilidade de transferência de riqueza. $\mathrm{O}$ cerne da Teoria consiste em o principal saber que irá perder parte de sua riqueza e, em compensação, procurar conseguir do agente os melhores desempenhos, ou seja, o principal deixa de obter o máximo para obter o possível dentro das condições colocadas, devido à participação de um administrador profissional (MENDES, 2001 apud ARRUDA, 2008). 
Nesse sentido, a Teoria da Agência busca analisar as relações internas e externas à empresa, bem como servir como modelo na tomada de decisões que envolva mais de um indivíduo, pois, de acordo com sua hipótese fundamental, sempre vai existir incongruência entre o comportamento desejado pelo principal e o comportamento apresentado pelo agente. Dessa forma, ela atua de modo a delimitar o conjunto de ajustes viáveis entre o principal e o agente e também tenta minimizar a assimetria informacional, caso em que principal e agente não possuem todas as informações necessárias para a análise dos contratos (ARRUDA, 2008, p.81).

A Teoria vem, nesse contexto, à busca para minimizar os conflitos e os custos dessa relação entre proprietário ou acionista com os "agentes"; aqueles designados para tomarem as decisões em seu nome, a fim de melhor utilizar os recursos empregados e gerar o retorno previsto pelo dono do capital. Para Silveira, Barros e Famá (2004, p.4), a governança corporativa é "o conjunto de mecanismos de incentivo e controle, internos e externos, para minimização dos custos decorrentes do problema de agência dos gestores" (apud CAMARGOS E BARBOSA, 2009, p.191). Logo, é necessário o entendimento sobre essa relação, pois a mesma reflete no desenvolvimento das políticas da empresa e particularmente do resultado, sendo uma arma de gestão.

\section{Instituto Brasileiro de Governança Corporativa}

O Instituto Brasileiro de Governança Corporativa foi instituído no dia 27 de novembro de 1995, sendo o responsável pela ampliação e divulgação das práticas de governança nos país. Com sede em São Paulo possui representações em quatro capítulos: MG, Paraná, Rio e Sul (IBGC, 2013).

Seu foco é a divulgação do conceito de governança, incentivo ao melhor resultado das organizações, desenvolvimento sustentável e direcionamento para que os agentes da sociedade no caminho da responsabilidade, justiça e transparência. Dentre as atividades o IBGC realiza fórum de debates e acadêmicos, treinamentos e networking entre profissionais, palestras, conferências, entre outras (IBGC, 2013).

$\mathrm{Na}$ sua composição o IBGC (2013) segue alguns valores: Proativismo: comprometimento com a capacitação de agentes e com o desenvolvimento e a 
disseminação das melhores práticas; Diversidade: valorização e incentivo à multiplicidade de idéias e opiniões; Independência: soberania nos princípios, zelo pela imagem e imparcialidade em face de quaisquer grupos de interesse; Coerência: entre iniciativas e princípios da governança corporativa, que são: Transparência: mais que a obrigação de informar é o desejo de disponibilizar para as partes interessadas as informações que sejam de seu interesse e não apenas aquelas impostas por disposições de leis ou regulamentos.

A adequada transparência resulta um clima de confiança, tanto internamente, quanto nas relações da empresa com terceiros. Não deve restringir-se ao desempenho econômico-financeiro, contemplando também os demais fatores (inclusive intangíveis) que norteiam a ação gerencial e que conduzem à criação de valor, as quais são: Equidade: caracterizase pelo tratamento justo de todos os sócios e demais partes interessadas (stakeholders). Atitudes ou políticas discriminatórias, sob qualquer pretexto, são totalmente inaceitáveis; Prestação de contas (accountability): os agentes de governança devem prestar contas de sua atuação, assumindo integralmente as conseqüências de seus atos e omissões; e
Responsabilidade Corporativa: os agentes de governança devem zelar pela sustentabilidade das organizações, visando à sua longevidade, incorporando considerações de ordem social e ambiental na definição dos negócios e operações.

O papel do IBGC ao reforçar a relevância das melhores práticas e adaptando as novas demandas e a realidade do mercado, é de fundamental importância e a revisão do Código caminha justamente nessa direção. $\mathrm{O}$ ambiente institucional brasileiro evoluiu muito desde a última revisão e o Código precisava, além de acompanhar essas mudanças, dar um passo a frente em relação ao que já é obrigatório para as organizações brasileiras (IBGC, 2013).

\section{Considerações finais}

Contextualizados os textos utilizados como referencial para este trabalho, convém retomar que a ética é o instrumento fundamental para a vida em conjunto, seja na sociedade primitiva ou em uma corporação moderna. O cenário acelerado de modificações, bem como a alta concorrência no mercado impõe às empresas novos desafios e demandas. Produtividade, lucratividade e 
compromisso social são exigências rotineiras como condições básicas para a sobrevivência das entidades.

Nesse contexto, nos últimos anos, tem aumentado a visão sob a perda de ética nas informações empresariais. Dessa forma, cria-se um grande desafio na área da Governança Corporativa em alinhar estratégias para resolver problemas do não cumprimento da ética. Segundo Vieira (2006, p. 24) “Todos devemos ser éticos tanto na vida profissional como familiar, entre outras relações em sociedade. Que nada mais é do que ser honesto, responsável, proceder sempre de forma que, senão puder ajudar, não atrapalhe".

A humanidade não teria criado civilizações sem a adoção dos conceitos éticos e morais. Estabelecendo que a Governança Corporativa deva proteger os direitos dos acionistas, tratando-os igualmente independentemente de serem minoritários, majoritários, nacionais ou estrangeiros; que as informações devem ser disponíveis e transparentes; divulgando-se oportunamente os fatos relevantes. O respeito pela informação e por quem dela necessita, é algo que precisa ser priorizado.

A gestão da ética nas informações e nas relações de trabalho é um dos pilares de consistência das empresas. As entidades que anseiam ter vida longa precisam estabelecer relações éticas com todos os seus públicos. Razão pela qual existe, entre as partes, um contrato determinando todos os detalhes, desde o modo do recolhimento dos dados a apresentação da informação lapidada.

Em negociações comerciais, a chave do negócio é ser ético. Apesar do comportamento antiético possa levar a ganhos imediatos, isso só acontece em curto prazo. Por outro lado, empresas que ordinariamente comportam-se de acordo com os mais elevados padrões éticos veem suas reputações subirem. Uma reputação adequada fará mais pela consistência das informações e pelo sucesso duradouro do que qualquer comportamento antiético.

Faz-se necessário teorizar menos e praticar mais, criando as condições para uma governança corporativa mais justa, mais humana, mais calcada em bons valores e comprometida com a verdade. Fala-se em ética, em crise de valores, em necessidade de mudança, de moralização, entre outros assuntos relacionados ao tema. Os empresários talvez tenham dificuldades em praticar a ética, procurar ter um comportamento ético, por saber que vão ter que abrir mão de algumas coisas, dificultando o desenvolvimento do ser ético. 


\section{Referências}

CALIL, Jose Francisco; MONOBE, Teruo; PEREIRA, Moacir. Ética, Responsabilidade Social e Governança Corporativa. 2 ed. São Paulo: Alínea, 2010.

DUPONT, Fernanda Prado de Medeiros. A Ética como Instrumento de Conduta do Profissional da Área Contábil. Cruz Alta-RS, 2010.

NEDEL, José. Os Gregos e Nós. São Leopoldo: UNISINOS, 2009.

SILVA, Edson Cordeiro. Governança Corporativas nas Empresas. São Paulo: Atlas, 2006.

VALLS, Álvaro L. M. O que é Ética. Brasiliense, 1994.

VIEIRA, Maria das Graças. A Ética na Profissão Contábil. 1 ed. São Paulo: Thomson, 2006. 